\title{
A deeper exploration of the relation between sulfonation degree and retanning performance of aromatic syntans
}

Qingyong Sun ${ }^{1,3}$, Yunhang Zeng ${ }^{1}$, Ya-nan Wang ${ }^{1}$, Yue Yu ${ }^{1,2}$ and Bi Shi ${ }^{1,2^{*}}$

\begin{abstract}
It is well-known that the sulfonation degree (DS) of aromatic syntan is an important factor affecting its retanning performances. But the quantitative relation between DS and syntan property and the influencing mechanism of DS on syntan property are not clarified. In this work, five phenolic formaldehyde syntans (PFSs) with the same polymerization degree but varying DS were prepared to investigate the effect of DS on the properties of syntan and crust leather. It was found that the absolute value of zeta potential and the particle size of PFS decreased with increasing DS in aqueous solution. Molecular dynamic simulation results proved that the DS of PFS was a major contributor to electrostatic interaction and hydrogen bonding in the PFS-water system and greatly affected the aggregation and dispersion of PFS in aqueous solution. The PFS with a low DS was prone to aggregate to large particles in aqueous solution because of low intermolecular electrostatic repulsion and less hydrogen bonds and therefore can be used to increase the thickness and tightness of leather. The PFS with a high DS presented a small particle size with more anionic groups in aqueous solution, thereby sharply decreasing the positive charge of leather surface and facilitating the penetration of the post-tanning agents into the leather. These results might be scientifically valid for rational molecular design of syntans and more productive use of syntans in leather making.
\end{abstract}

Keywords: Sulfonation degree, Aromatic syntan, Aggregation, Penetration, Molecular dynamics simulation

\footnotetext{
*Correspondence: shibi@scu.edu.cn

1 National Engineering Laboratory for Clean Technology of Leather

Manufacture, Sichuan University, Chengdu 610065, China

Full list of author information is available at the end of the article
}

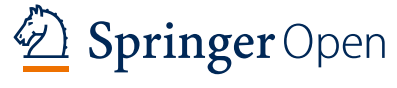

(c) The Author(s) 2021. Open Access This article is licensed under a Creative Commons Attribution 4.0 International License, which permits use, sharing, adaptation, distribution and reproduction in any medium or format, as long as you give appropriate credit to the original author(s) and the source, provide a link to the Creative Commons licence, and indicate if changes were made. The images or other third party material in this article are included in the article's Creative Commons licence, unless indicated otherwise in a credit line to the material. If material is not included in the article's Creative Commons licence and your intended use is not permitted by statutory regulation or exceeds the permitted use, you will need to obtain permission directly from the copyright holder. To view a copy of this licence, visit http://creativecommons.org/licenses/by/4.0/. 


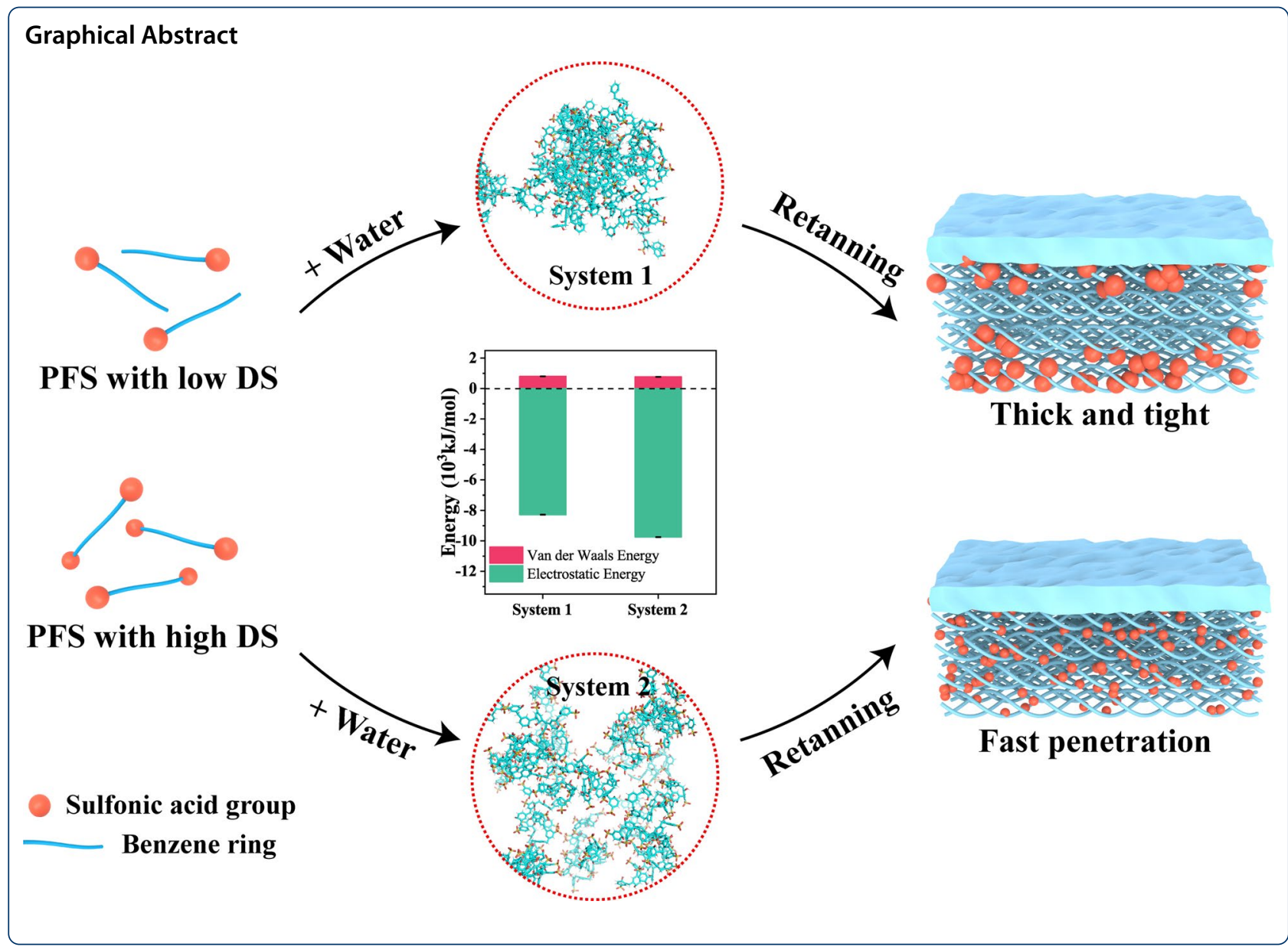

\section{Introduction}

Retanning has become indispensable for modern leather manufacturing because it can reduce differences in various parts of leather, increase the yield of leather, and endow leather with proper fullness and elasticity [1-3]. Commonly used retanning agents include aromatic syntans, amino resins, acrylic resins, and aldehyde derivatives $[4,5]$. Aromatic syntans, especially phenolic syntan, have received much attention due to their advantages of filling property, dispersibility, and bleachability [6]. Aromatic syntans are generally prepared through condensation, sulfonation, and other reactions by using phenol or naphthalene, formaldehyde, and concentrated sulfuric acid as raw materials, thereby having hydrophobic benzene/naphthalene rings and hydrophilic sulfonic acid groups $[7,8]$. Sulfonation degree (DS), which represents the portion of sulfonic acid groups in aromatic syntan, is a key factor that influences the retanning performance of leather according to tanners' practical experience. For example, an aromatic syntan with low DS often has strong tanning property and is used as a replacement retanning agent, whereas a syntan with high DS generally has good solubility and weak tanning property and is used as an auxiliary retanning agent (e.g., dispersant and neutralizer).

Previous research mainly focused on the selection of new monomers for synthesis of novel or high-performance syntans $[9,10]$. The effect of the DS of aromatic syntan on retanning performance is usually evaluated by tanner's experience because the penetration and distribution of aromatic syntan in leather have never been directly visualized or quantified. Hence, the quantitative relationship between the DS of aromatic syntan and its retanning performance remains unclear. Fully understanding the relationship is essential to develop new syntans and choose rational syntans for achieving better retanning performance and leather quality.

In this study, phenolic formaldehyde syntans (PFSs) with the same polymerization degree and different DSs were prepared and used as aromatic syntan models to investigate the effects of DS on the charge property and particle size of syntan, the penetration and uptake of syn$\tan$ in leather, and the organoleptic properties of crust leather. Moreover, intermolecular interactions of PFS in 
water were explored through molecular dynamics (MD) simulation. The changes in the surface charge of retanned leather were analyzed to further explain why DS greatly affects the properties of PFS and retanned leather.

\section{Materials and methods}

\subsection{Materials}

Chrome tanned cattle hide with a thickness of $1.2 \mathrm{~mm}$ and $\mathrm{Cr}_{2} \mathrm{O}_{3}$ content of $4.5 \%$ was purchased from Zhejiang Haining Ruixing Leather CO., Ltd. (China). Phenol, formaldehyde, sulfuric acid, and other reagents used for PFS analysis were of analytical grade and purchased from Chengdu Kelong Chemical Co., Ltd. (China). Chemicals used for leather processing were of commercial grade and provided by Sichuan Decision New Material Technology Co., Ltd. (China).

\subsection{Preparation of PFSs with different DSs}

PFSs with different DSs were prepared through condensation and sulfonation (Fig. 1). A dehydrated intermediate, namely, phenolic formaldehyde condensate $(\mathrm{PF})$, was prepared using phenol and formaldehyde as raw materials according to literature [11]. In brief, $94.1 \mathrm{~g}$ phenol $(1 \mathrm{~mol})$ and $20.0 \mathrm{~g}$ sulfuric acid solution (20 wt\%, $0.04 \mathrm{~mol}$ sulfuric acid) were added into a four-neck flask equipped with a thermometer, a mechanical stirrer, and a flush condenser. Then, $52.7 \mathrm{~g}$ formaldehyde solution (37 $\mathrm{wt} \%, 0.65 \mathrm{~mol}$ formaldehyde) was added drop-wisely at $60^{\circ} \mathrm{C}$ within $2 \mathrm{~h}$. The mixture was reacted at $90{ }^{\circ} \mathrm{C}$ for another $3 \mathrm{~h}$. After that, the condensates were cooled, separated, washed, and vacuum dried. As a result, a mixture of ortho and para PFs were obtained. The phenol hydroxyl content of PF determined by titration method was $9.7 \mathrm{mmol} / \mathrm{g}$, the polymeric degree determined by electrospray ionization mass spectrometry ranged from 3 to 7 (Additional file 1: Fig. S1), and the average molecule weight determined by gel permeation chromatography was $573 \mathrm{~g} /$ mol (Additional file 1: Table S1). Then, $103 \mathrm{~g}$ of PF was separately sulfonated using $20,40,60,80$, and $100 \mathrm{~g}$ of concentrated sulfuric acid at $110{ }^{\circ} \mathrm{C}$ for $3 \mathrm{~h}$. After sulfonation, the mixtures were neutralized and lyophilized to obtain five types of PFSs with different DSs.

\subsection{Determination of DS of PFS}

In brief, $2 \mathrm{~g}$ of sulfonated PF without neutralizing was diluted with $50 \mathrm{~mL}$ of distilled water in a flask. The sulfonated $\mathrm{PF}$ solution was titrated to $\mathrm{pH} 7.2$ by adding sodium hydroxide solution $(0.5024 \mathrm{~mol} / \mathrm{L})$. The DS of PFS was calculated by Eq. (1):

$$
\operatorname{DS}(\%)=\frac{c \times\left(V_{1}-V_{2}\right)}{\mathrm{n}_{[\mathrm{OH}]}} \times 100
$$

where $c$ is the concentration of sodium hydroxide solution, $V_{1}$ is the equivalent volume of sodium hydroxide solution consumed by $1 \mathrm{~g}$ of the mixture of PF and sulfuric acid according to sulfonation reaction recipes, $V_{2}$ is the equivalent volume of sodium hydroxide solution consumed by $1 \mathrm{~g}$ of sulfonated PF $(\mathrm{mL} / \mathrm{g})$, and $n_{[\mathrm{OH}]}$ is the phenolic hydroxyl content per $1 \mathrm{~g}$ of sulfonated $\mathrm{PF}$ ( $\mathrm{mmol} / \mathrm{g})$.

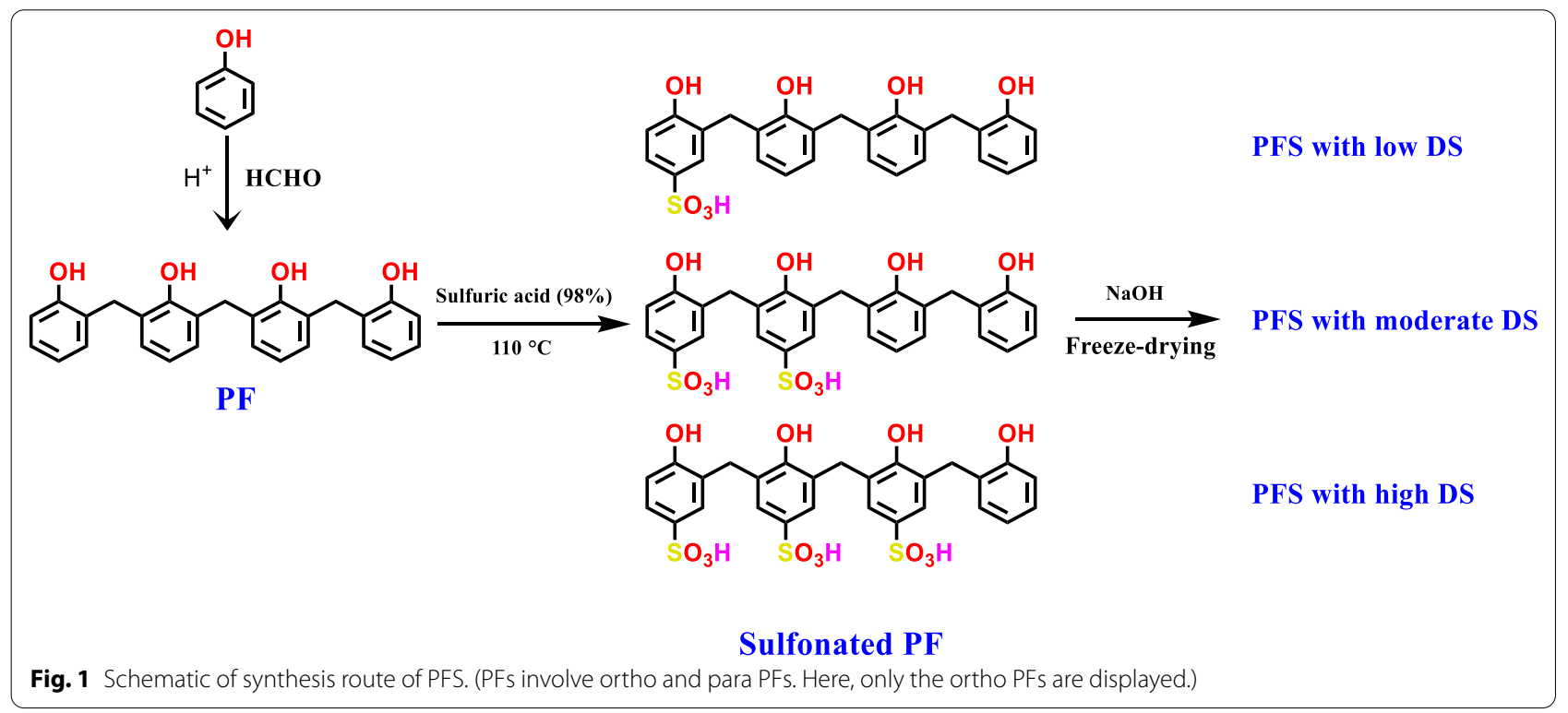




\subsection{Determination of zeta potential and particle size of PFS}

The zeta potentials of PFSs aqueous solutions $(1.0 \mathrm{~g} / \mathrm{L})$ in the $\mathrm{pH}$ range of 3.0-6.5 and the particle size distributions of PFSs in aqueous solution $(1.0 \mathrm{~g} / \mathrm{L})$ at $\mathrm{pH} 6.5$ were determined by using a zeta potential and laser particle size analyzer (Nano ZS90, Malvern, UK). All the measurements were undertaken at $25{ }^{\circ} \mathrm{C}$ after the aqueous solution samples were treated with ultrasonic for $10 \mathrm{~min}$ and equilibrated for $3 \mathrm{~min}$. The measurement was repeated three times for each sample.

\subsection{MD simulation}

Two analogs of PFS (Fig. 2a, b) were selected as models of low DS PFS (L-PFS) and high DS PFS (H-PFS), respectively. L-PFS consists of five phenol units and one sulfonic acid unit, and H-PFS consists of five phenol units and three sulfonic acid units. The DSs of L-PFS and $\mathrm{H}-\mathrm{PFS}$ were $20 \%$ and $60 \%$, respectively, which were close to those of the prepared PFS-18 (DS $=18 \%)$ and PFS-63 (DS $=63 \%$ ). The MD simulation of L-PFS-water system and H-PFS-water system (Table 1) was carried out at $300 \mathrm{~K}$ and $1 \mathrm{~atm}$ to simulate the aggregation behavior of PFSs with different DSs in aqueous solution. The Optimized Potentials for Liquid Simulations/All Atom (OPLS/AA) force field was employed to describe the intramolecular and intermolecular interactions of the models [12]. The TIP4P [13] model was used to describe the water molecule. Before MD simulation, the initial structures of L-PFS and H-PFS were optimized through density functional theory (DFT) by using the B3LYP functional at the $6-311 \mathrm{G}++(\mathrm{d}, \mathrm{p})$ basis set. The configurations of the two systems were generated using the PACKMOL package [14]. $\mathrm{Na}^{+}$ions were added to neutralize the negative charges of sulfonate groups in the models. All molecular simulations were performed using
Table 1 Simulation details

\begin{tabular}{lllll}
\hline System & $\begin{array}{l}\text { Model } \\
\text { molecule }\end{array}$ & $\begin{array}{l}\text { Number } \\
\text { of model } \\
\text { molecule }\end{array}$ & $\begin{array}{l}\text { Number } \\
\text { of water } \\
\text { molecule }\end{array}$ & Volume $\left(\mathbf{n m}^{\mathbf{3}}\right)$ \\
\hline System 1 & L-PFS & 60 & 7200 & 255.06 \\
System 2 & H-PFS & 60 & 7200 & 262.84 \\
\hline
\end{tabular}

the GROMACS package [15] (version 2019.6), where the model molecules were placed in a cubic box and periodic boundary conditions were applied to the $\mathrm{x}, \mathrm{y}$, and $\mathrm{z}$ directions. First, the two systems were energy minimized using steepest descent minimization method for 10,000 steps. The systems were equilibrated successively in canonical NVT and NPT ensemble for 500 ps. Finally, production runs were performed for $100 \mathrm{~ns}$. Berendsen barosatat [16] and Langevin dynamics methods [17] were used to control the pressure and temperature, respectively. A time step of $2 \mathrm{fs}$ was used for all simulations, and the bond lengths were kept rigid using the LINCS algorithm [18]. A cutoff distance of $12.0 \AA$ was defined for all non-bonded interactions. Particle mesh Ewald method [19] was used to treat long-range electrostatic interactions. Simulation trajectory data were analyzed using Visual Molecular Dynamics (VMD) software [20], and non-bond interactions including electrostatic interaction, van der Waals force, and hydrogen bonding were analyzed using the build-in modules of GROMACS.

\subsection{Retanning and fatliqouring}

Eighteen pieces of shaved wet blue $(30 \mathrm{~cm} \times 30 \mathrm{~cm}$ for each) were first rewetted and chrome retanned according to conventional processes. Pieces No. 1-6 were neutralized to $\mathrm{pH} 4.5$. Pieces No. 7-12 were neutralized to $\mathrm{pH}$ 5.5. Pieces No. 13-18 were neutralized to $\mathrm{pH} 6.5$. These neutralized leather samples were retanned with

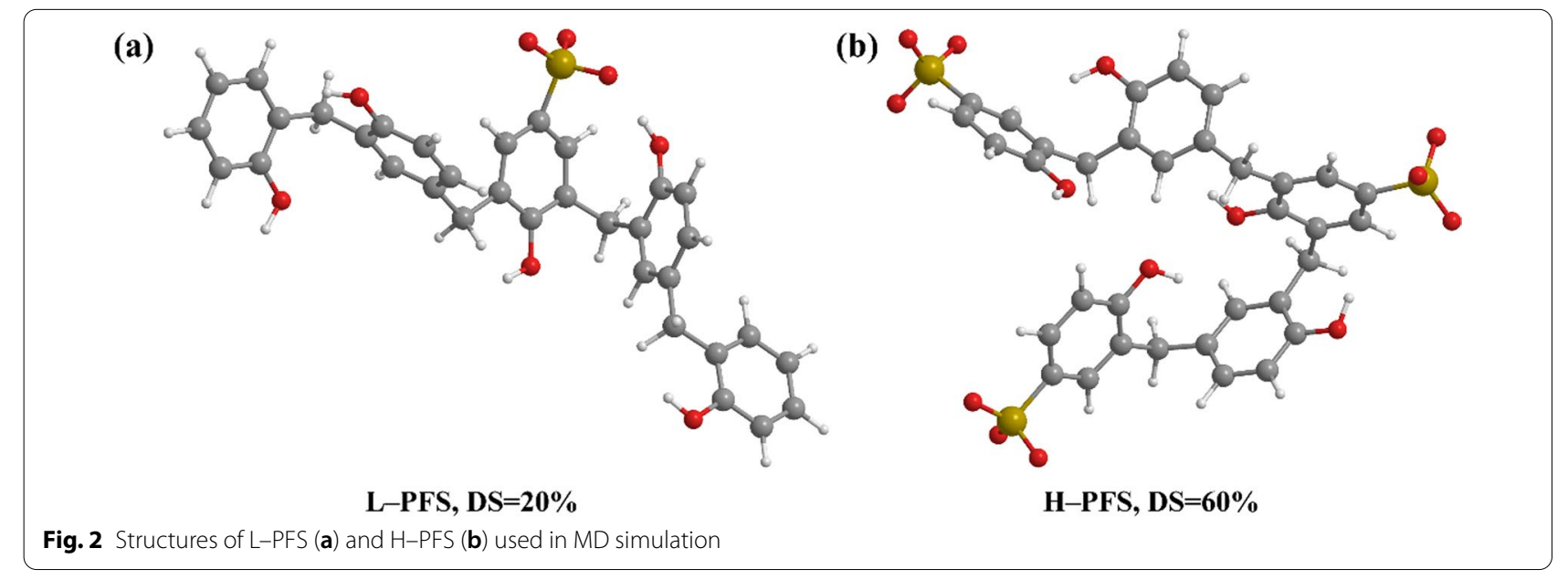


PFS (Table 2). Another eighteen pieces of leather samples were neutralized as above and then retanned and fatliqoured as shown in Table 3. The crust leather without PFS retanning was used as the control.

\subsection{Determination of zeta potential and pls of retanned leather}

The zeta potentials of the retanned leather samples (No. 13-18) with $\mathrm{pH}$ ranging from 3.0 to 9.0 were determined according to our previously reported method [21] by using a Zeta potential analyzer (Mütek SZP-10, BTG, Germany). The $\mathrm{pH}$ at zero point of zeta potential for the determined system was identified as the pI of the leather.

\subsection{Analysis of PFS penetration in leather}

The penetration of PFS (reddish brown) in leather (blue) was analyzed by observing the vertical section of the retanned leather with a stereo microscope (SZX12, Olympus, Japan). The relative content of PFS in leather was obtained by processing the micrograph with Image J software [22]. The penetration rate of PFS in the leather was calculated by Eq. (2) [23]:

$$
\text { Penetration rate }(\%)=\frac{\text { Area of leather with PFS }}{\text { Total area of leather }} \times 100
$$

\subsection{Determination of uptake rate of PFS by leather}

The concentrations of total organic carbon (TOC) in the initial and final retanning baths were measured using a TOC tester (Vario TOC, Elementar Co., Ltd., Germany) and recorded as $\mathrm{TOC}_{\text {ini }}$ and $\mathrm{TOC}_{\text {res }}$, respectively. The uptake rate of PFS was calculated by Eq. (3):

$$
\text { Uptake rate }(\%)=\frac{\mathrm{TOC}_{\mathrm{ini}}-\mathrm{TOC}_{\mathrm{res}}}{\mathrm{TOC}_{\mathrm{ini}}} \times 100
$$

\subsection{Determination of thickness increase rate of leather} The thicknesses of PFS retanned and fatliqoured leathers were measured using a thickness gauge (MY-3130-A2, Ming Yu Electron Tech Information Co., Ltd., China) and recorded as $\delta_{1}$. The thickness of fatliqoured leather without PFS retanning was measured and recorded as $\delta_{0}$. The thickness increase rate of the leather caused by PFS retanning was calculated by Eq. (4):

$$
\text { Thickness increase rate }(\%)=\frac{\delta_{1}-\delta_{0}}{\delta_{0}} \times 100
$$

\subsection{Determination of leather softness}

The staked crust leathers were conditioned at $20{ }^{\circ} \mathrm{C}$ and $65 \% \mathrm{RH}$ for $48 \mathrm{~h}$. The softness of the crust leather samples was determined according to the standard (IUP 3).

Table 2 Retanning process

\begin{tabular}{llllll}
\hline Process & Chemicals & Dosage $^{\mathbf{a}}(\%)$ & Temperature $\left({ }^{\circ} \mathbf{C}\right)$ & Time $(\mathbf{m i n})$ & Remark \\
\hline Retanning & Water & 200 & 35 & 120 & \\
& PFS $^{b}$ & 15 & & $15 \times \mathrm{n}$ & $\begin{array}{l}\text { pH 3.8-4.0. Collect } \\
\text { effluent and leather } \\
\text { Fomples }\end{array}$ \\
& Formic acid & $0.5 \times \mathrm{n}$ & & & samples
\end{tabular}

${ }^{a}$ The percentage of chemicals was based on the weight of shaved wet blue

\begin{tabular}{|c|c|c|c|c|c|}
\hline Process & Chemicals & Dosage $^{a}(\%)$ & Temperature $\left({ }^{\circ} \mathrm{C}\right)$ & Time (min) & Remark \\
\hline \multirow[t]{2}{*}{ Retanning } & Water & 200 & 35 & 120 & \\
\hline & $\mathrm{PFS}^{\mathrm{b}}$ & 15 & & & \\
\hline \multirow[t]{2}{*}{ Fatliqouring } & Synthetic fatliqour & 8.0 & & 60 & \\
\hline & Formic acid & $0.5 \times n$ & & $15 \times n$ & $\mathrm{pH} 3.8$, drain \\
\hline Washing & Water & 200 & & 10 & \\
\hline $\begin{array}{l}\text { Vacuum drying at } 50^{\circ} \mathrm{C} \text { for } 3 \mathrm{~min} \text {, } \\
\text { hang-drying and staking }\end{array}$ & & & & & $\begin{array}{l}\text { Collect crust } \\
\text { leather sam- } \\
\text { ples }\end{array}$ \\
\hline
\end{tabular}

${ }^{b}$ The PFSs were the prepared PFS-18, PFS-33, PFS-50, PFS-63, and PFS-74, respectively (number presents DS)

Table 3 Retanning and fatliqouring processes

${ }^{a}$ The percentage of chemicals was based on the weight of shaved wet blue

${ }^{\mathrm{b}}$ The PFSs were the prepared PFS-18, PFS-33, PFS-50, PFS-63, and PFS-74, respectively (number presents DS) 


\section{Results and discussion}

\subsection{Effect of DS on zeta potential and particle size of PFS}

This study mainly aimed to determine the effect of the DS of PFS on retanning performance. Five PFSs that had the same polymerization degree and different DSs were prepared. The DSs of these PFSs are shown in Fig. 3a. DS affects the surface charge and aggregation behavior/particle size of the retanning agents, which mostly determine the penetration and uptake of retanning agents in leather. Therefore, the effects of DS on the zeta potential and particle size of PFS were investigated.

Figure $3 \mathrm{~b}$ shows the zeta potentials of various PFS solutions. The increase in the absolute value of zeta potential is correlated with the decrease in the DS of PFS and the increase in the $\mathrm{pH}$ of the PFS solution. The former phenomenon could be explained by the aggregation of PFS. The PFS molecules aggregated into a colloid that consisted of a hydrophobic core stacked with benzene rings and a hydrophilic shell with abundant sulfonic acid groups $[7,8,24]$. And the latter phenomenon was due to the deprotonation of phenolic hydroxyl and sulfonic acid groups in PFS. Figure 3c shows that the average particle size of PFS increases with decreasing DS. This means that the PFS with lower DS aggregates into larger particles in aqueous solution.

MD simulation is an effective method used to explore intermolecular interactions, such as electrostatic interaction, van der Waals force, and hydrogen bonding. Figure 4a presents the snapshots of Systems 1 and 2 at 0 and 100 ns. L-PFS molecules assemble and form large clusters, whereas H-PFS disperses well in the aqueous solution. The result is consistent with the particle size data in Fig. 3c.

Figure $4 \mathrm{~b}$ shows that $\mathrm{H}-\mathrm{PFS}$ is more disperse in aqueous solution than L-PFS due to its lower potential energy. The absolute value of electrostatic energy is higher than that of van der Waals energy (Fig. 4c), indicating that the electrostatic interaction is a major contributor to the aggregation and dispersion of the PFS-water system.
Additionally, the absolute value of electrostatic energy for the $\mathrm{H}$-PFS-water system is higher than that for the LPFS-water system, indicating that high DS is beneficial to the dispersion of PFS in water. The average number of hydrogen bonds formed by $\mathrm{H}-\mathrm{PFS}$ and water is higher than that formed by L-PFS and water (Fig. 4d) because $\mathrm{H}-\mathrm{PFS}$ has more sulfonic groups. This finding explains why $\mathrm{H}-\mathrm{PFS}$ has higher solubility than L-PFS in aqueous solution. Hence, the DS of PFS is an important contributor to electrostatic interaction and hydrogen bonding in the PFS-water system, which greatly affects the aggregation behavior/particle size of PFS in the aqueous solution.

\subsection{Effect of DS of PFS on pl of retanned leather}

As shown in Fig. 5, the pI of the chrome retanned leather (control) is about 7.9, and the pIs of the leather samples retanned with PFS are reduced to less than 5.3. This is due to the introduction of the sulfonic acid and phenolic hydroxyl groups in PFS to hide collagen. The pIs of the retanned leather samples were reduced from 5.3 to 3.6 as the DS of PFS increased from 18 to $74 \%$. Increasing DS results in a decrease in the $\mathrm{pI}$ of the retanned leather. This is because the sulfonic acid and phenolic hydroxyl groups in PFS can combine with the amino groups of collagen and chrome in leather [25]. Within $\mathrm{pH}$ 4.5-6.5, the retanned leather possessed lower zeta potential with increasing DS, which should be helpful for the penetrations of PFS and other post-tanning agents in the leather.

\subsection{Effect of DS on penetration of PFS in retanned leather}

Retanning performance is closely related to the penetration depth of syntan in leather. In this section, the penetrations of PFSs with different DSs in leather samples neutralized to $\mathrm{pH} 4.5,5.5$, and 6.5 were analyzed. The visual distributions, relative contents, and penetration rates of PFS in the leather are shown in Figs. 6a-c, respectively. The penetration depth of PFS in leather at the same neutralizing $\mathrm{pH}$ increases with increasing DS of PFS. The main reason for this should be the fact that
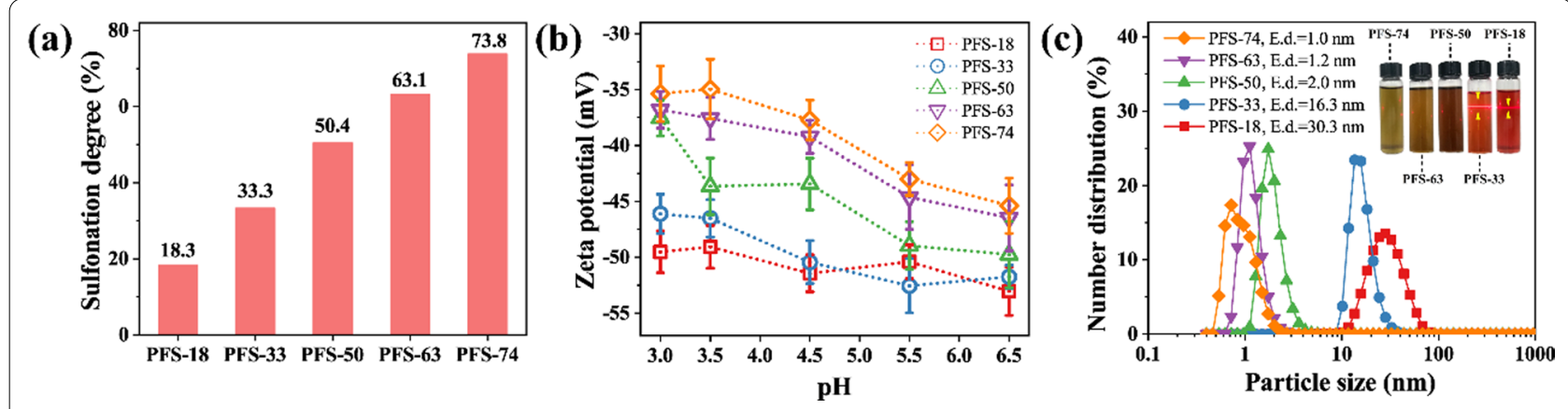

Fig. 3 a DS of PFS; $\mathbf{b}$ effect of DS on zeta potential of PFS; $\mathbf{c}$ distribution of particle size of PFS in aqueous solution 

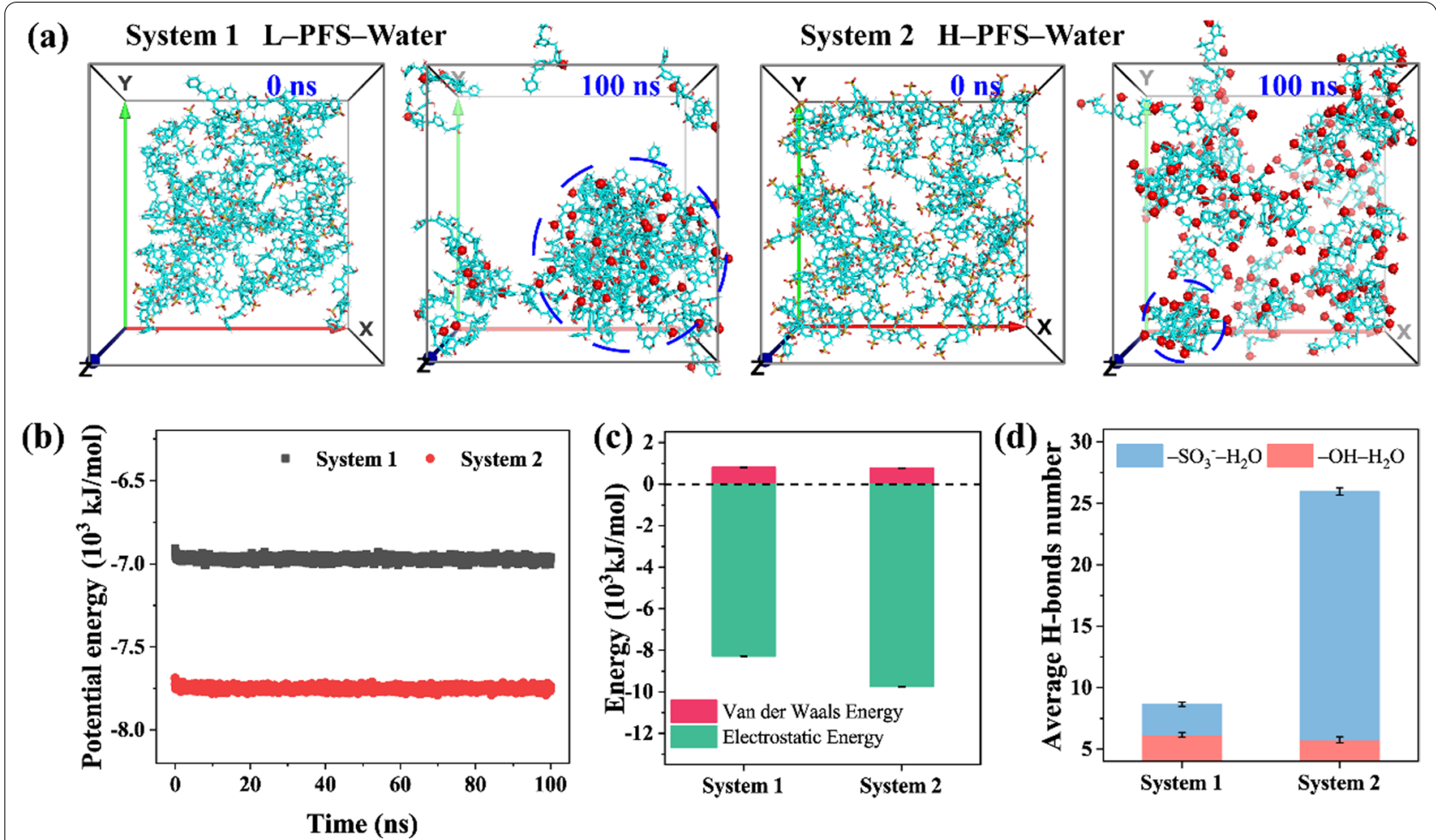

Fig. 4 a Snapshots of MD simulation systems 1 and 2 (water molecules are left off for better visual clarity, red ball represents sulfonic acid group); b potential energy; c electrostatic and van der Waals energies; $\mathbf{d}$ average number of hydrogen bonds formed by phenol hydroxyl and sulfonic acid groups of PFS and water from 50 to 100 ns

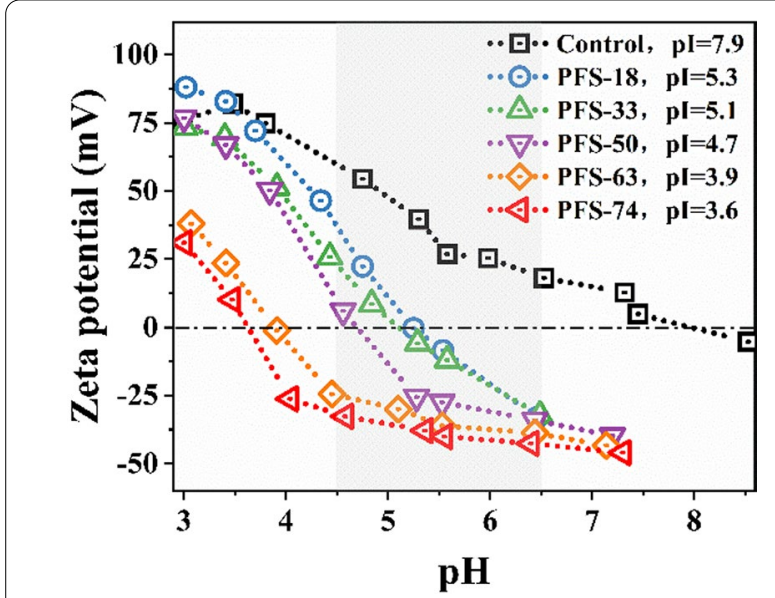

Fig. 5 Isoelectric points (pls) of leather samples retanned using PFS with different DSs (neutralizing pH 6.5)

the positive charge of neutralized leather decreased more remarkably when the leather combined with PFS having more anionic groups (Fig. 5), which consequently reduced the electrostatic attraction between leather surface and PFS. Another reason is that the particle size of PFS decreases with increasing DS. The two reasons contribute to reduction in the PFS transfer resistance, thereby increasing the penetration depth of PFS in the leather.

All PFSs did not fully penetrate the leather samples neutralized to $\mathrm{pH} 4.5$ mainly because of the strong electrostatic attraction (binding force) between the leather surface (zeta potential, $54.4 \mathrm{mV}$ ) and PFSs (zeta potential, $-51.4 \mathrm{mV}$ to $-37.7 \mathrm{mV}$ ). As the neutralizing $\mathrm{pH}$ increased to 5.5 , the zeta potential of leather reduced sharply to $26.8 \mathrm{mV}$, and the zeta potentials of PFSs $(-50.4 \mathrm{mV}$ to $-43.0 \mathrm{mV})$ were slightly lower than those at $\mathrm{pH}$ 4.5. As a result, the mass transfer resistance caused by the electrostatic attraction between the leather surface and PFS weakened, and the penetration of PFS in the leather increased. When the $\mathrm{pH}$ of the leather sample was neutralized to 6.5 , the zeta potential of the leather was reduced to $18.0 \mathrm{mV}$, and PFSs with DS higher than $50 \%$ completely penetrated the leather. These results clearly and quantitatively verify that a high DS of PFS and a high neutralization $\mathrm{pH}$ of leather favor the penetration of PFS in leather. 


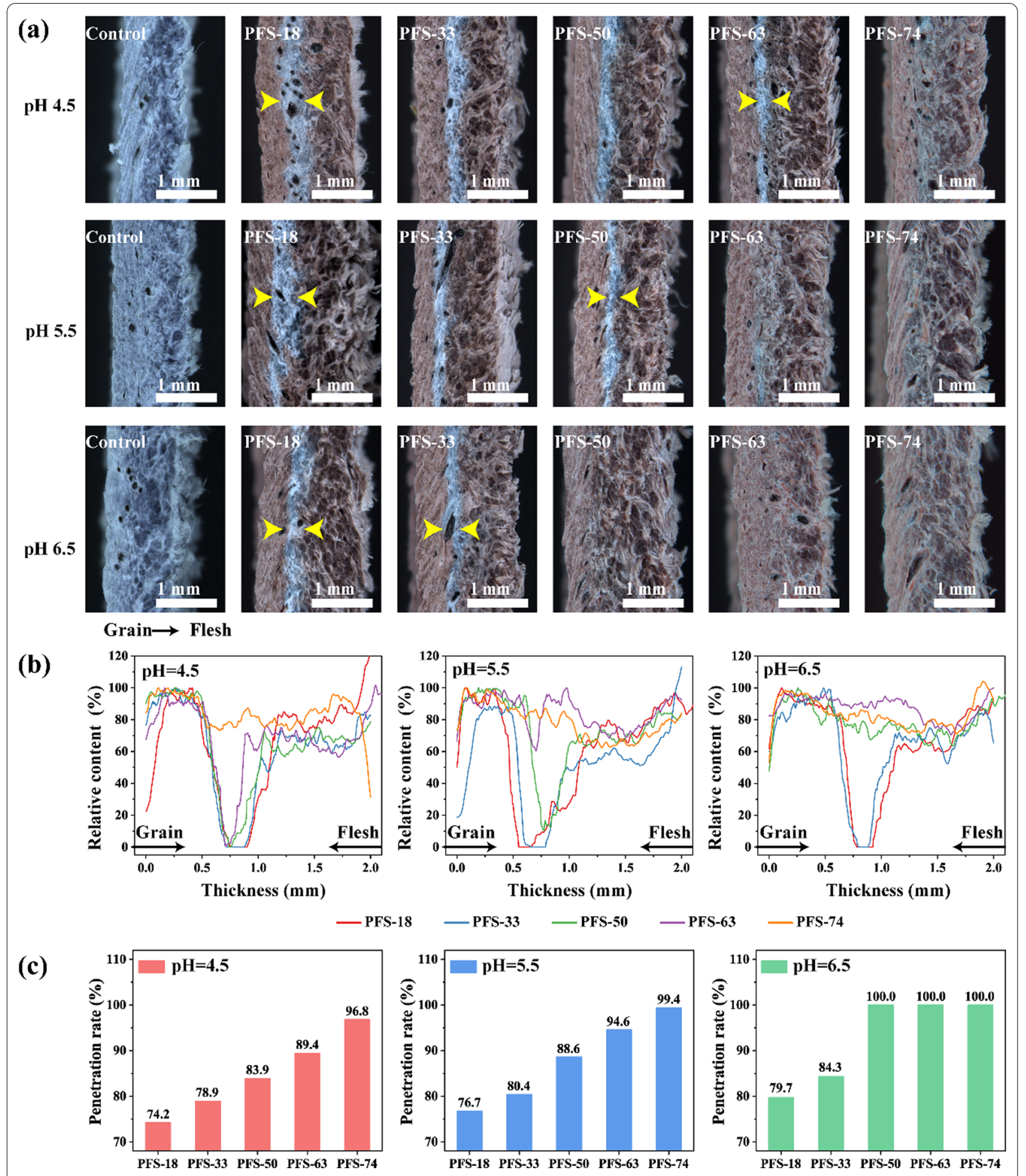

Fig. 6 a Micrographs of vertical sections of PFS retanned leather samples (scale bar, $1 \mathrm{~mm}$ ); $\mathbf{b}$ relative contents of PFS in retanned leather; $\mathbf{c}$ penetration rates of PFS in retanned leather 


\subsection{Effect of DS on uptake of PFS by leather}

As shown in Fig. 7, the uptake rates of PFS by leather decreased with increasing DS of PFS because a higher DS of PFS made leather have less positive charge at fixation $\mathrm{pH}$ of 3.8, thereby reducing the electrostatic attraction between PFS and leather. Moreover, the neutralizing $\mathrm{pH}$ had little effect on the uptake of PFS by the leather because the fixation $\mathrm{pH}$ was as low as 3.8 , ensuring that the leather had positive charge to form bonds with PFS. The uptake rate of PFS-74 was the lowest but still reached more than $84 \%$. This may be due to the fact that the particle size of PFS is relatively small and could enter small gaps among collagen fibers besides large gaps.

\subsection{Effect of DS of PFS on thickness and softness of crust leather}

Retanning has received much attention in the leather processing since it can improve the handle of leather, such as thickness and tightness [26, 27]. The effects of DS of PFS on the thickness and softness of crust leather were

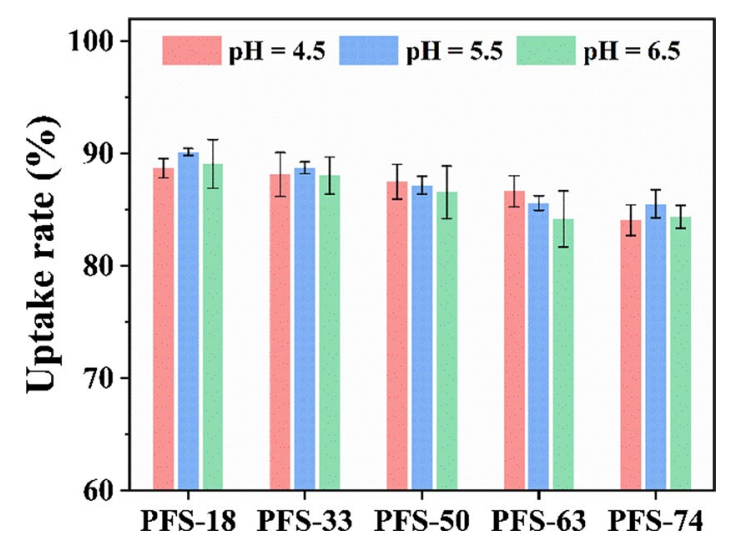

Fig. $\mathbf{7}$ Uptake rates of PFSs by retanned leather samples analyzed (Fig. 8). The increase rate of leather thickness decreased, and the softness increased as the DS of PFS increased. The PFS with low DS can form large aggregates and fill large pores among collagen fibers, thereby increasing the thickness and tightness of the leather. These results suggest that thickness and tightness of leather can be regulated using PFSs with different DSs.

It is worth noting that the neutralization $\mathrm{pH}$ has a greater impact on the softness of crust leather than the DS of PFS (Fig. 8b). This is because the surface charge of retanned leather decreased more sharply with the increase in neutralization $\mathrm{pH}$ than with increasing DS (Fig. 5), and less positive charges of the retanned leather was more beneficial to the penetration of fatliqour. However, a high neutralization $\mathrm{pH}$ may pose a risk of leather looseness. Therefore, it is better to regulate the penetration of post-tanning chemicals through rational combination of neutralization and DS selection.

\section{Conclusions}

Intermolecular interactions, such as electrostatic interaction, van der Waals force, and hydrogen bonding, determine the aggregation behavior/particle size of PFS in aqueous solution. The PFS with low DS contains less sulfonic acid groups, and thus results in lower intermolecular electrostatic repulsion and smaller amount of hydrogen bonds in the PFS-water system. In this regard, PFS with low DS aggregates into large particles in aqueous solution. The PFS with high DS includes more sulfonic acid groups, and therefore leads to higher intermolecular electrostatic repulsion in the PFS-water system. As such, PFS with high DS is more disperse in aqueous solution and has a small particle size. The PFS with low DS is suitable for increasing the thickness and tightness of leather, and the PFS with high DS is helpful for reducing the positive charge of leather surface
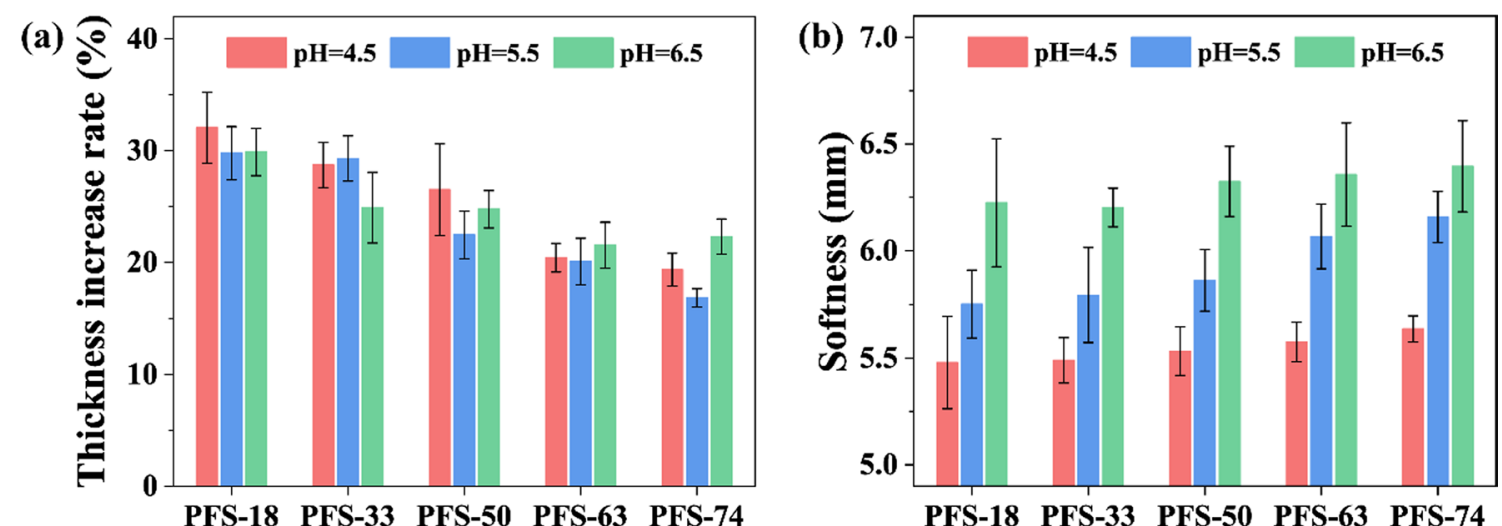

Fig. 8 a Thickness increase rate and $\mathbf{b}$ softness of crust leather retanned by PFS with different DSs 
and promoting the penetration of anionic chemicals in leather.

\section{Supplementary Information}

The online version contains supplementary material available at https://doi. org/10.1186/s42825-021-00073-0.

Additional file 1: Figure S1. Electrospray ionization mass spectrometry spectrum of PF. Table S1. Molecular weight distributions of PF and PFSs.

\section{Acknowledgements}

Not applicable.

\section{Authors' contributions}

QS developed the methodology, performed the experiments, analyzed the data and wrote the initial draft. YZ analyzed the data and revised the manuscript. YW analyzed the data. YY performed the experiments and analyzed the data. BS formulated the research goals and aims, supervised the project, and revised the manuscript. The authors read and approved the final manuscript.

\section{Funding}

This work was supported by the National Natural Science Foundation of China (21978176).

\section{Availability of data and materials}

All data generated or analyzed during this study are included in this manuscript. The authors declare that the data in this article are reliable.

\section{Declarations}

\section{Competing interests}

The authors declare that they have no competing interests.

\section{Author details}

${ }^{1}$ National Engineering Laboratory for Clean Technology of Leather Manufacture, Sichuan University, Chengdu 610065, China. ${ }^{2}$ Key Laboratory of Leather Chemistry and Engineering (Sichuan University), Ministry of Education, Chengdu 610065, China. ${ }^{3}$ Sichuan Decision New Material Technology Co., Ltd., Deyang 618000, China.

Received: 5 October 2021 Accepted: 18 November 2021 Published online: 15 December 2021

\section{References}

1. Wu C, Zeng YH, Liao XP, Zhang WH, Shi B. Effect of retanning agents on dry heat resistance of leathers. J Am Leather Chem Assoc. 2013;108(8):294-9.

2. Bosch T, Manich AM, Carilla J, Palop R, Cot J. Characterization of retanned chrome bovine leather by thermomechanical analysis. J Appl Polym Sci. 2001;82(2):314-22. https://doi.org/10.1002/app.1854.

3. Tang KY, Zheng XJ, Yang M, Liu J, Shelly DC, Casadonte DJ. Influence of retanning on the adsorption capacity of water on cattlehide collagen fibers. J Am Leather Chem Assoc. 2009;104(11):367-74.

4. De Nicola E, Meric S, Gallo M, laccarino M, Della Rocca C, Lofrano G, et al. Vegetable and synthetic tannins induce hormesis/toxicity in sea urchin early development and in algal growth. Environ Pollut. 2007;146(1):46-54. https:// doi.org/10.1016/j.envpol.2006.06.018.

5. Zou XL, Lan YJ, Zhang QH, Zhan XL. Synthesis and mechanical properties of polyacrylic acid resin retanning agent. J Soc Leather Technol Chem. 2014;98(3):127-30.

6. Ammenn J, Huebsch C, Schilling E, Dannheim B. Chemistry of syntans and their influence on leather quality. J Am Leather Chem Assoc. 2015;110(11):349-55.

7. Chen L, Dou J, Ma Q, Li N, Wu R, Bian H, et al. Rapid and near-complete dissolution of wood lignin at degrees $\mathrm{c}$ by a recyclable acid hydrotrope. Sci Adv. 2017;3(9): e1701735. https://doi.org/10.1126/sciadv.1701735.
8. He D, Wang Y, Yoo CG, Chen Q-J, Yang Q. The fractionation of woody biomass under mild conditions using bifunctional phenol-4-sulfonic acid as a catalyst and lignin solvent. Green Chem. 2020;22(16):5414-22. https://doi. org/10.1039/d0gc01722a.

9. Feng GT, Shan ZH, Shao SX, Jiang L. Preparation and tanning powers of syntan with sulphone. Leather Sci Eng. 2003;06:50-3.

10. Chen YJ, Zhang WH, Huang JH, Shi B. Synthesis of aromatic syntan scp and its tanning performance investigation. Leather Sci Eng. 2014;24(04):5-10.

11. Lu KT, Luo KM, Lin SH, Su SH, Hu KH. The acid-catalyzed phenol-formaldehyde reaction: critical runaway conditions and stability criterion. Process Saf Environ Prot. 2004;82(1):37-47. https://doi.org/10.1205/095758204322777 651.

12. Jorgensen WL, Maxwell DS, TiradoRives J. Development and testing of the opls all-atom force field on conformational energetics and properties of organic liquids. J Am Chem Soc. 1996;1 18(45):11225-36. https://doi.org/10. 1021/ja9621760.

13. Jorgensen WL, Chandrasekhar J, Madura JD, Impey RW, Klein ML. Comparison of simple potential functions for simulating liquid water. J Chem Phys. 1983;79(2):926-35. https://doi.org/10.1063/1.445869.

14. Martinez L, Andrade R, Birgin EG, Martinez JM. Packmol: a package for building initial configurations for molecular dynamics simulations. J Comput Chem. 2009;30(13):2157-64. https://doi.org/10.1002/jcc.21224.

15. Hess B, Kutzner C, van der Spoel D, Lindahl E. Gromacs 4: Algorithms for highly efficient, load-balanced, and scalable molecular simulation. J Chem Theory Comput. 2008;4(3):435-47. https://doi.org/10.1021/ct700301q.

16. Berendsen HJC. Nuclear magnetic resonance study of collagen hydration. J Chem Phys. 1962;36(12):3297-305. https://doi.org/10.1063/1.1732460.

17. Ghodsi H, Darvish K. Investigation of mechanisms of viscoelastic behavior of collagen molecule. J Mech Behav Biomed Mater. 2015;51:194-204. https:// doi.org/10.1016/j.jmbbm.2015.07.015.

18. Hess B, Bekker H, Berendsen HJC, Fraaije JGEM. Lincs: a linear constraint solver for molecular simulations. J Comput Chem. 1997;18(12):1463-72.

19. Darden T, York D, Pedersen L. Particle mesh ewald: an $n \cdot \log (n)$ method for ewald sums in large systems. J Chem Phys. 1993;98:10089-92. https://doi. org/10.1063/1.464397.

20. Humphrey W, Dalke A, Schulten K. Vmd: visual molecular dynamics. J Mol Graph. 1996;14(1):33-8. https://doi.org/10.1016/0263-7855(96)00018-5.

21. Wang YN, Huang WL, Zhang HS, Tian L, Zhou JF, Shi B. Surface charge and isoelectric point of leather: a novel determination method and its application in leather making. J Am Leather Chem Assoc. 2017;112(7):224-31.

22. Schindelin J, Arganda-Carreras I, Frise E, Kaynig V, Longair M, Pietzsch T, et al. Fiji: an open-source platform for biological-image analysis. Nat Methods. 2012;9(7):676-82. https://doi.org/10.1038/nmeth.2019.

23. Wang H, Lei C, Zeng YH, Song Y, Zhang QX, Shi B. Reversible inhibition of trypsin activity with soybean flour in hide bating process for leather quality improvement. Ind Crop Prod. 2021;161:1-7. https://doi.org/10.1016/j.inder op.2020.113222.

24. Smith MD, Mostofian B, Cheng XL, Petridis L, Cai CM, Wyman CE, et al. Cosolvent pretreatment in cellulosic biofuel production: effect of tetrahydrofuranwater on lignin structure and dynamics. Green Chem. 2016;18(5):1268-77. https://doi.org/10.1039/c5gc01952d.

25. Jankauskaite V, Jiyembetova I, Gulbiniene A, Sirvaityte J, Beleska K, Urbelis V. Comparable evaluation of leather waterproofing behaviour upon hide quality. I. Influence of retanning and fatliqouring agents on leather structure and properties. Mater Sci Medziagotyra. 2012;18(2):150-7. https://doi.org/ 10.5755/j01.ms.18.2.1918.

26. Sun XP, Jin Y, Lai SQ, Pan JZ, Du WN, Shi $\sqcup$. Desirable retanning system for aldehyde-tanned leather to reduce the formaldehyde content and improve the physical-mechanical properties. J Clean Prod. 2018;175:199-206. https://doi.org/10.1016/j.jclepro.2017.12.058.

27. Zhang JW, Cheng F, Ai ZW, Chen WY. The synthesis and application of phosphorus-nitrogen flame retardant retanning agent. Rev Pielarie Incaltaminte. 2015;15(3):188.

\section{Publisher's Note}

Springer Nature remains neutral with regard to jurisdictional claims in published maps and institutional affiliations. 